\title{
Correction to: Advanced Methods for Processing and Visualizing the Renewable Energy
}

Samsul Ariffin Abdul Karim $\mathbb{D}^{\text {, }}$, Nordin Saad, and Ramani Kannan

\section{Correction to:}

S. A. Abdul Karim et al. (eds.), Advanced Methods

for Processing and Visualizing the Renewable Energy, Studies in Systems, Decision and Control 320, https://doi.org/10.1007/978-981-15-8606-4

The original version of the book was inadvertently published with incorrect affiliation (city name) of the editors in the frontmatter, which has now been corrected from "Seri Iskandar, Selangor, Malaysia" to "Seri Iskandar, Perak, Malaysia". The erratum book has been updated with the changes. 